\title{
Designing and Modeling of Automated Anti-theft Electricity Distribution System
}

\author{
Awais Khan ${ }^{1}$, Wei Xie ${ }^{1}$, Suhail Aftab Qureshi ${ }^{2}$, Muhammad llyas ${ }^{3}$, JingChun Lin ${ }^{4}$ and Guidong Liu ${ }^{4}$ \\ ${ }^{1}$ College of Automation Science and Technology, South China University of Technology, Guangzhou 510641, China \\ ${ }^{2}$ Electrical Engineering Department, UET Lahore, Pakistan \\ ${ }^{3}$ Iqra International University Peshawar, Pakistan \\ ${ }^{4}$ College of Electrical and Information Engineering, GuangDong Baiyun University, Guangzhou 51045, China
}

\begin{abstract}
In this modern era electricity is the major component of human life. Its play a vital role to facilitate the human life by operating all modern electrical equipment. The consumption of electricity increases rapidly due to its uses in the domestic and industrial sector. In the distribution of electricity, there are few emerging issues leads to huge losses. The illegal connection of electricity in remote areas increases rapidly. Such theft of electricity from distribution line leads to huge losses in revenue of electricity. Pakistan facing huge energy crisis due to a shortage of electricity generation. This research project modeled and the designed the hardware prototype of automated anti-theft electricity distribution system. The proposed system detects the illegal load and burns it by sending high voltage signal from capacitor bank. The legal load is made safe and uninterrupted during execution of illegal load.
\end{abstract}

\section{Introduction}

Distribution of electricity is the major responsibility of the National Transmission and Dispatch (NTDC) company limited.As the length of the transmission line increases from generation plant causes an increase in line losses and another issue. Theft of electricity from distribution line in form illegal connection directly from the transmission line is the major issue in the collection of revenue. It is quite difficult for government institutions to check twenty-four the user connection to ensure $100 \%$ revenue. Such issue can be handled with the help technology development based on automation industry. It is a big challenge for NTDC to detect and handle such illegal connection from distribution line (DL). Each year, the electricity distribution companies face $20 \%$ to $25 \%$ line losses. According to WAPDA survey, these losses are round about 125 billion a year. These losses can destroy the power system of a country. Due to these losses, more than $20 \%$ consumers pay extra money.

There are two kinds of losses occurs in these systems.

1. Technical

2. Non-Technical

Losses due to structure and characteristics of the network are called Technical losses, while losses due to the stealing of electricity are called Non-technical losses. If someone is using electricity illegally, it is a silent crime [1]. Due to these losses government give a big relief to these companies [2], [3].

Generally, power system consists of three parts (1) Generation (2) Transmission (3) Distribution which is different from each other by their voltage values.
Generally, the generation phase and transmission phase is far away from the city. So, the people cannot access them easily. The next phase that is the distribution phase is inside the city which is easily accessible to the people and within this phase, the main problem starts. The voltage level is also low that can be used directly.

To use electricity illegally there are many ways like (a) To decrease speed of meter by using hard metallic disks (b) Using large magnet disturbing electromagnetic field of electric meter (c) Taking connection directly from the distribution lines without using electric meter (d) By switching the electricity cables at meter connector box [4]. Our proposed research project is handling the direct contact from distribution line. It will detect and control the theft load by burning it. The controller portion can easily differentiate the legal and illegal or theft load. To handle the theft of electricity by tapping the meter in digital meter microprocessor will be used to record the value of their unit. Communication block is used to synchronize and analyze the values of power used at any instant. The stored values of power will be transmitted to the distributor. In detection block, if there will any mismatch between input power and output power microprocessor will detect it. If there is any illegal connection, then detection block will tell the reporting block to transmit the information to the respective authority through GSM module [4-5].

The energy billing system in Pakistan and all over the world can be changed using this system. This system of energy billing may help the energy distribution companies to minimize costs and increase 


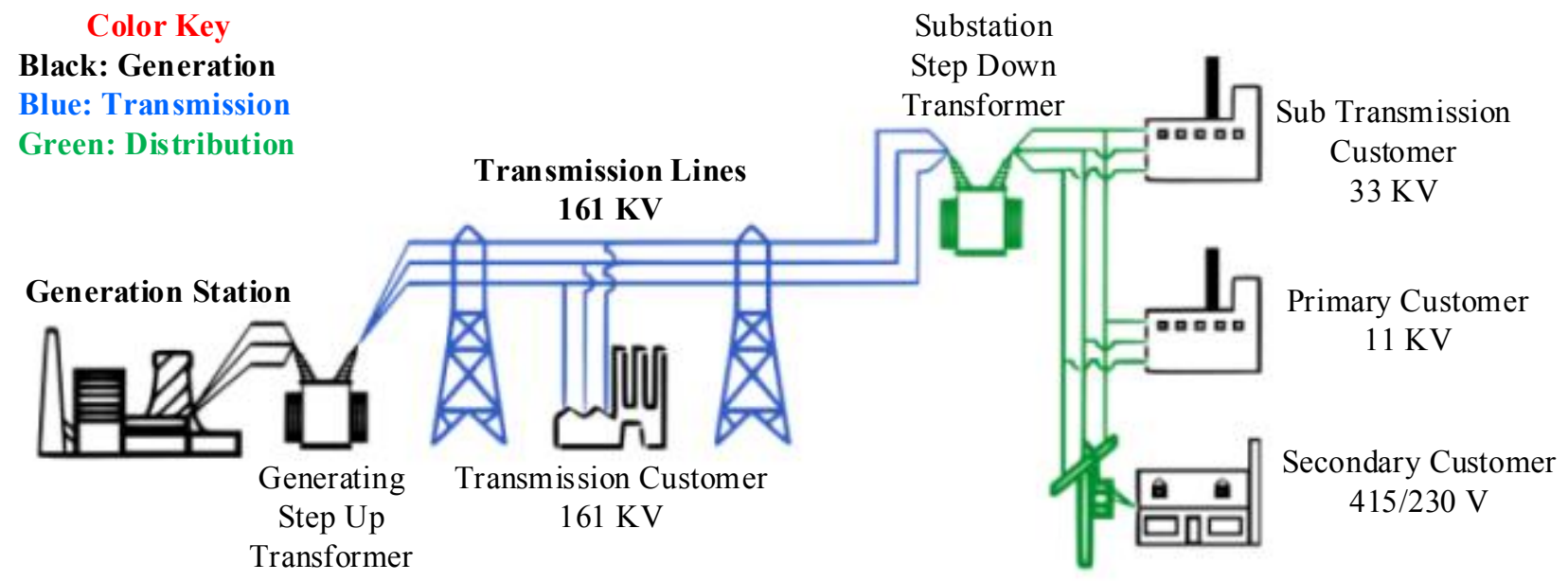

Figure 1. A general model of Electricity generation, transmission, and distribution system.

profits, to increase metering and billing accuracy and efficiency, and to contribute the energy in a sustainable way. Moreover, theft will also be reduced and theft load will burn as a penalty. The final advantage that makes this system superior then others is that: this system didn't use any communication module for theft detection so the system uses a common controller for comparing the power of consumer and distribution unit.

The proposed method is distributed in three stages.

1. Transmission phase

2. Distribution phase

3. User phase

At distribution phase, the power is stepped down by step down transformer and then supplied to the user. At this stage, adjustable rating circuit breakers will be used on connections of every user, due to the installation of these circuit breakers no user will exceed his required limit of load, if any user will cross the required limit the circuit breaker will be tripped and will be disconnected from supply. At user stage where conventional meters are used, will be replaced by smart meters having features of two-way communication system [6].

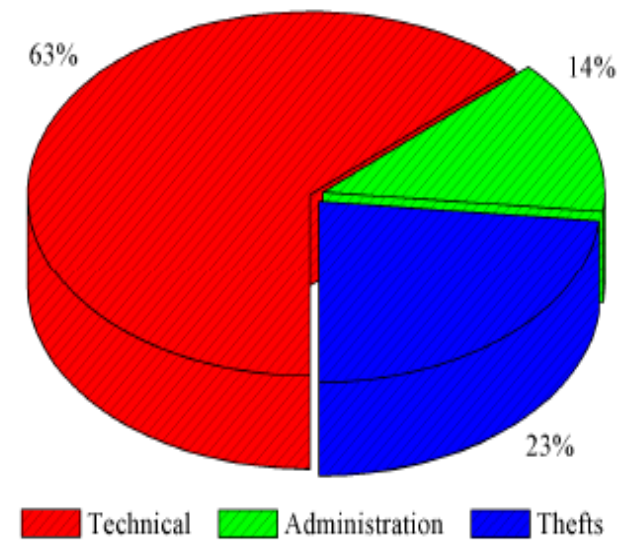

Figure 2. Estimated sources of grid losses.
The above figure represents that there are $23 \%$ theft losses amongst $100 \%$ lines losses. Technical losses are due to the design of the distribution network, the length of cables, transformers and loads. Technical losses are about $63 \%$ of total losses. Administration losses are due to by giving unknown connections or missing meters not illegal use of electricity. The administration losses are about $14 \%$ of total losses [6], [7], [8].

The goal of the project is to make a system which automatically detects and control illegal connection of electricity, the proposed project is about such automated system which will differentiate between actual and theft load and will control the theft of electricity by burning the theft load.

1. To make an algorithm that will give instruction to the microcontroller to monitor and control the theft load.

2. To design a microcontroller based system that will monitor and control actual and theft.

3. To implement a prototype of a smart WAPDA system.

This project includes building a hardware for the system, interfacing the hardware i.e. interfacing the microcontroller with relay driver, and interfacing different components like relays, energy meters, and capacitor bank.

This project will be very suitable for WAPDA because theft losses are one of the major problems of WAPDA due to this project WAPDA will overcome such losses and this project will also burn the theft loads as a penalty.

The proposed research project is organized as Section 3 defines the proposed scheme and model, Section 4 explains the software implementation. Section 5 is based on results and conclusion of the proposed scheme. Finally, Section presents the future recommendation.

\section{Existing methods}

In [9] G. L. Prashanthi, K. V. Prasad had proposed with GSM modules helps the company to monitor the amount of usage by this specified customer and generate bill periodically and send it to the customer via SMS, thus 
saving a lot of labor work, time and cost of reading. The proposed found to be a little bit complex as far as a distribution network is concerned, but it's an automated system of theft detection. It saves time as well as help to maximize profit margin for utility company working in electrical distribution network while in [10] S.Anusha, M.Madhavi, R.Hemalatha had done the project model to reduces the manual manipulation work and theft. Use of GSM in our system provides numerous advantages of the wireless network system. The government saves money by the control of theft in energy meter and also more beneficial for customer side and the government side. The metering IC ensures the accurate and reliable measurement of power consumed. Cost wise low when compared to another energy meter without automatic meter reading and theft control. In the paper [11] Kalaivani. R, Gowthami. M, Savitha.S, Mohanvel.S had done the system, in which service provider can collect the bill any time with a single message. The data collection and manipulation task become fast and easier. Any modification can be made to the code in less time. Changes in rate or unit calculation can be done very effectively. The project model reduces the manual manipulation work and theft. Use of GSM in our system provides the numerous advantages of wireless network systems. The metering IC ensure the accurate and reliable measurement of power consumed. Hence we are trying to manipulate cost wise low when compared to another energy meter without automatic meter reading and theft control. In some of the existing methods wireless communication system of energy meter used with Zigbee [12-13], relay control and GPRS [14-15]. The cryptographic method is used to secure the communication channel [16-17]and Zigbee for the transmission of data in a serial process [18-19].

\section{Proposed scheme}

The main goal of this paper is to design such smart system which will detect and prevent electricity theft. So for this purpose, some smart microprocessor based modifications will be used to locate the presence of electricity theft. The figure below shows the methodology of the proposed solution.

This goal can be obtained by comparing power supplied to the consumer and power used by the consumer. In measurement block flow of power will be calculated, in case of digital meter it will directly fetch the numeric value but in case of an analog meter, some extra infrared transmitter and receiver circuitry will be used to detect the revolution of the disk. So for continuous monitoring of power microprocessor will be used to record the values. Communication block is used to synchronize and analyze the values of power used at any instant. The stored values of power will be transmitted to the distributor. In detection block, if there will any mismatch between input power and output power microprocessor will detect it and there must be an illegal connection. If there is any illegal connection detection block will tell the reporting block which will transmit the information to the respective authority through GSM module. Now it is the responsibility of respective authorities to take action [5].

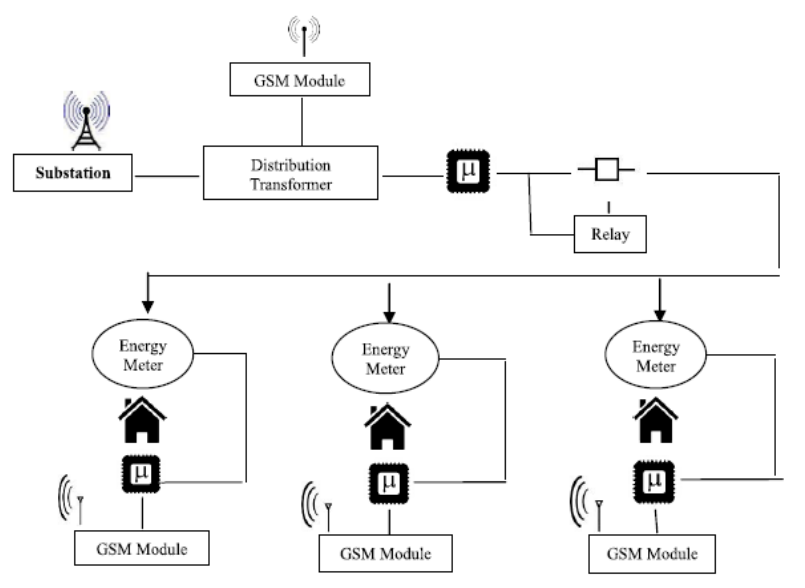

Figure 3. A birds eye view of methodology.

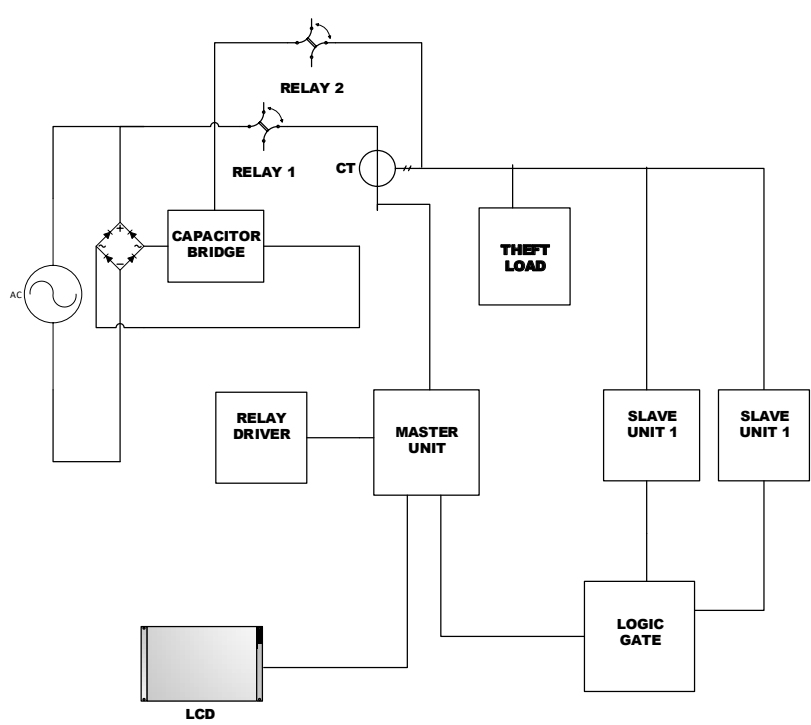

Figure 4. Block diagram of automated anti-theft electricity distribution system.

According to the block diagram shown below, the $220 \mathrm{v}$ AC supply is connected to relay 1 and bridge rectifier. Relay 1 is further connected to current transformer and slave units as well as bridge rectifier relates to capacitor bank having the ability to charge up to $600 \mathrm{v}$ DC. This circuitry is further connected with relay 2. Slave units relate to logic gates and it connected with the master unit. Master unit relates to LCD and relay driver. When there is AC supply through relay 1 slave units (meters) will be $\mathrm{ON}$ and bridge rectifier will convert $\mathrm{AC}$ supply to DC and charge capacitor bank. Capacitor bank relates to relay 2 that means relay 2 is always connected with high voltage DC, during normal operation when there is no theft load relay 2 is OFF and relay 1 is ON, whenever there is theft load relay 1 will be OFF and relay 2 will be turned ON and it will burn the theft load because it is high voltage DC. All these decisions are made by a master unit which collects data from current transformer and slave units whenever input of current transformer and output of slave units is equal circuits operates normally and whenever data is not equal it sends 
signals to relays with the help of relay driver and the circuit operates accordingly.

\section{Software implementation}

Before implementing the hardware, the circuit must be put under test, for the sake of simplicity, so that error checking and testing of the programming can be performed. Here Proteus version 8 is used to simulate the system.

Design of slave unit 1 and slave unit 2 that are energy meters are designed in Proteus version 8. Vsm signal generator is used for voltage and frequency source, as we increase the level of Vsm generator value of current changes as shown in below figure, the below figure shows the function of energy meter of calculating power consumption.

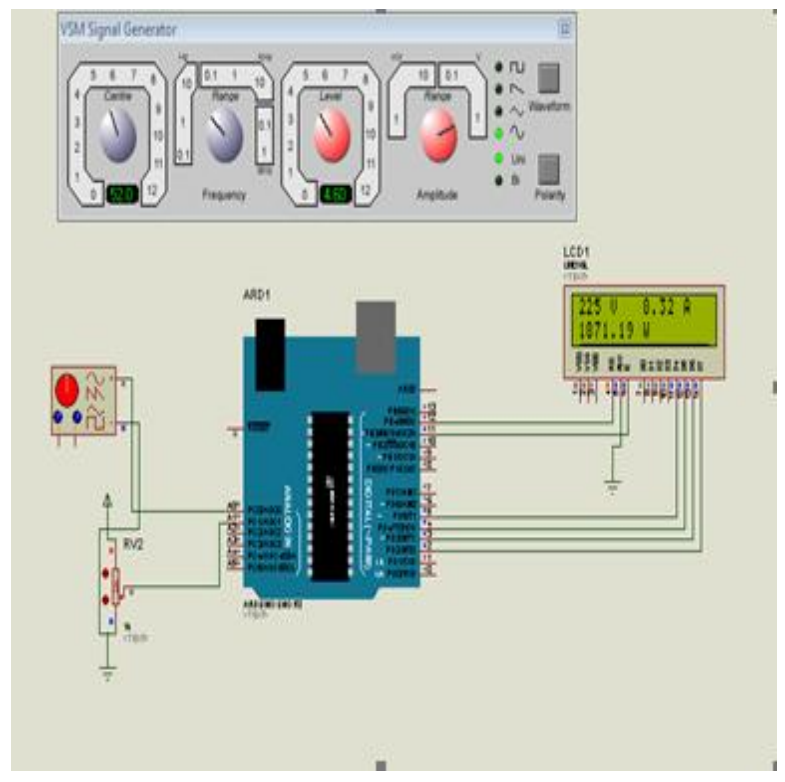

Figure 5(a). Simulation result of slave units.

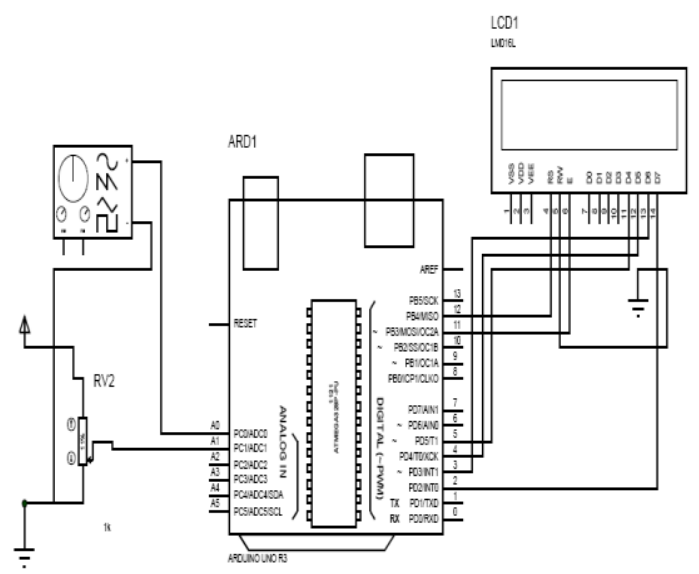

Figure 5(b). Circuit diagram of slave units.

For measuring the AC current, a current transformer (C.T) is used, where potential transformer (P.T) is used to measure the voltage of AC system .while C.T and P.T signals are sinusoidal so it will be converted to DC using bridge rectifier [8]. These signals will be transferred to the controller for displaying the information on LCD. All the information will be displayed on LCD. The figure 4 shown below indicates the LCD information. Here 3 potentiometers are used to check whether the system is running ok or not. Are the voltage and current value changes according to the change in resistance or not? After simulating the circuit, it was found that coding of the system and hardware is accurate according to demand. All the things are working ok, where the controller is sensing the theft and informing the controller which take necessary action i.e. turn off the official load and sending high voltage to the theft load, which basically damages the appliance.

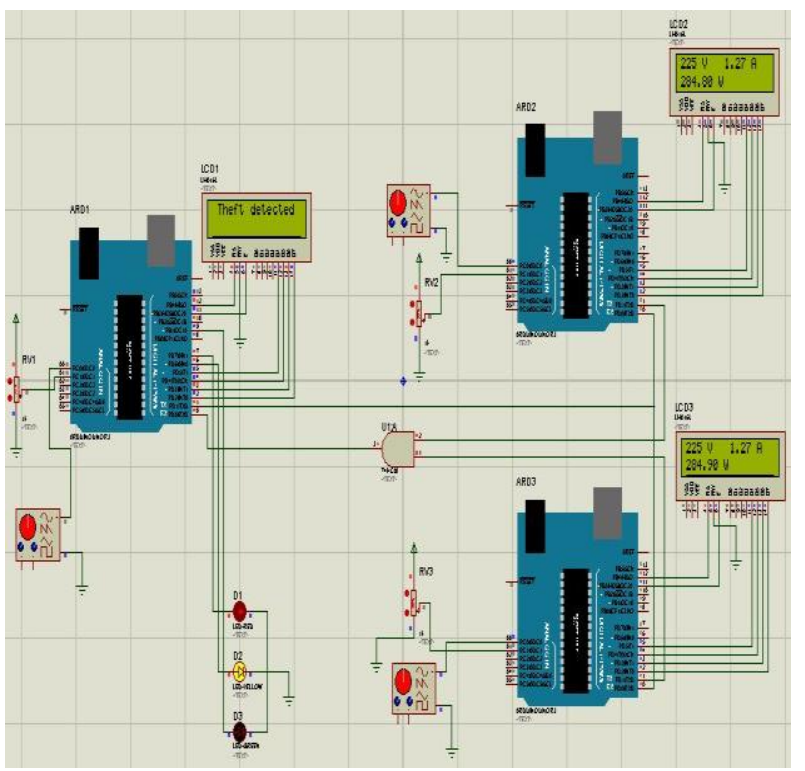

Figure 6. Simulation of the automated anti-theft electricity distribution system.

\section{Results and conclusion}

In this paper a verified idea for measuring the electrical power utilization of a load for two wire (phase and neutral) systems with the projected energy meter as a substitute to the conventional meters. This controllerbased power meter has been applied (prototype) to deliver quantity up to $200 \mathrm{~W}$ load from a 220 to $260 \mathrm{~V}$ line to neutral voltage. The planned energy meter can calculate power consumption for all loads situations. It doesn't own any rotating parts, which is a striking feature for the efficacies. The proposed meter includes a no-load threshold feature that will remove any tiptoeing effects in the energy meter. In addition, the process of reading the power consumption is smoothed by the LCD display that is very much closer than that for the analog power meters which decrease human errors while noting down the meter reading. Moreover, the system will be used to minimize the theft of electricity by sending HVDC on the theft load.

Automation in electricity distribution system can leads to smart distribution system with application of 
modern control strategy. The proposed project introduces a remarkable idea for controlling the theft load losses in electricity distribution system. The legal load is made safe and uninterrupted. The achieved results of hardware design can be further improved by determining the exact position of theft load with the application of advanced communication technologies.

\section{Future recommendations}

As our system have some limitations which can be overcome in future. This system is designed for two wireline system. A system that can be used for a four wire line system can be considered in future.

\section{Acknowledge}

This work was supported by Natural Science Foundation of Guangdong Province(2017A030313385), Science and Technology Project of Guangdong Province (2016B090927007,2017A040403064 ; 2017B090901040, 2017A040405023).

\section{References}

1. Depuru, S. S. S. R., Wang, L., Devabhaktuni, V., \& Gudi, N. (2010, September). Measures and setbacks for controlling electricity theft, NAPS, 2010 (pp. 18). IEEE.

2. Mogilenko, A. V., and D. A. Pavlyuchenko. "Expert System for Efficiency Comparison of Electric Network Companies, IJTPE, Transaction on Power Engineering 1 (2009): 1-4.

3. Ramos, Caio CO, et al. "Fast non-technical losses identification through optimum-path forest, ISAP'09. 15th International Conference on. IEEE, 2009.

4. Aslam, Farhan, et al. "Intelligent Modeling Scheme for Detection of Line Losses in Power Distribution System." Computer Modelling and Simulation (UKSim), 2013 UKSim 15th International Conference on. IEEE, 2013.

5. Mehran University Research Journal of Engineering and Technology, Volume 32, No. 3, July 2013 [SSN 0251-7821].

6. Kadurek, Petr, et al. "Theft detection and smart metering practices and expectations in the Netherlands." 2010 IEEE PES, ISGT Europe. IEEE, 2010 .
7. Thomas B. Smith Department of Social and Behavioral Sciences, Zayed University, P.O. Box 19282, Dubai.

8. Dr. Mohd Yunus B Nayan1, Aryo Handoko Primicanta 2009. Hybrid System Automatic Meter Reading. ICCTD -09, pp : 264-267.

9. G. L. Prashanthi, K. V. Prasad "Wireless Power Meter Monitoring with Power Theft Detection and Intimation system using GSM and Zigbee Networks" IOSR Journal of Electronics and Communication Engineering (IOSRJECE), Volume 9, Issue 6, Ver. I (NOV.-DEC. 2014).

10. S.Anusha, M.Madhavi, R.Hemalatha "Detection of Power Theft using GSM" IJARTET Volume 1, Issue 3, Nov 2014.

11. Kalaivani. R, Gowthami. M, Savitha.S, Mohanvel.S "GSM Based Electricity Theft Identification in Distribution System” IJETT - Volume 8 Number 10 - Feb 2014.

12. Abhinandan Jain, Dilip Kumar, Jyoti Kedia, 'Design and Development of GSM based Energy Meter', in IJERT, 2012.

13. S. Arun, Dr. Sidappa Naidu, "Design and Implementation of Automatic Meter Reading System Using GSM, ZIGBEE through GPRS” in IJARCSSE, 2012.

14. Young Hoon Lim, Moon Suk Chain, Jong Mock Baek, Sang-Yeom Lee "An An Efficient Home Energy Management System Based on Automatic Meter Reading” in IEEE International Symposium on Power Line Communication, 2011.

15. Xiujie Dong, Yan Yang, You Zhou "The Design of Wireless Automatic Meter Reading System Based on $S O P C$ ” in WASE ICIE, 2010 IEEE.

16. Syed Shahbaz Ali, Madiha Maroof, Sidrah Hanif "Smart Energy Meter for Energy Conservation and Minimizing Errors" in International Conference on Power Electronics, 2010.

17. Dr. Mohd Yunus B Nayan1, Aryo Handoko Primicanta "Hybrid System Automatic Meter Reading” in Proceeding of the ICCTD, 2009.

18. Vinu V Das, “Wireless Communication System for Energy Meter Reading” in International Conference on ARTCom, 2009.

19. Bharath, P. Ananth, N. Vijetha, S. Prakash, K.V.J. "Wireless Automated Digital Energy Meter" in Sustainable Energy Technologies, ICSET 2008. 